\section{A prospective study of 18 infants of chronic HBsAg mothers}

Sir,

I read with interest the paper by Mollica et al. ${ }^{1}$ and should like to add the results of our prospective study for comparison with other Mediterranean countries on 37 HBsAg mothers who were found among 1002 pregnant women attending a maternity hospital. Although $3.7 \%$ of the mothers were positive for HBsAg, only in $0.1 \%$ of cord blood specimens was HBsAg demonstrable by counter electrophoresis. ${ }^{2} 15$ of the babies of $\mathrm{HBsAg}$ mothers were followed up every 2 months for a 4- to 9month period for $\mathrm{HBsAg}$ determinations. Only one baby became HBsAg-positive during this time, without any evidence of hepatitis. $12.8 \%$ of our neonatal hepatitis cases are HBsAg-positive using the same method.

Anti-HBs was present in the sera of 2 mothers, and in the cord bloods of their babies, without HBsAg being present.

\section{References}

1 Mollica F, Musumeci S, Rugolo S, Mattina T. A prospective study of 18 infants of chronic HBsAg mothers. Arch Dis Child 1979; 54: 750-4.

2 Özsoylu S. About viral hepatitis. Turk J Pediatr 1975; 17 : 69-77.

SINASI ÖZSOYLU Hacettepe University, Institute of Child Health 609, Hacettepe, Ankara, Turkey

Professor Mollica and co-workers comment:

Professor Özsoylu gives additional data concerning maternofetal transmission of hepatitis B virus infection obtained in a Mediterranean country with a fairly high prevalence of HBsAg carriers. The figures for HBsAg positivity in cord bloods $(1: 37)$ and sera at follow-up $(1: 15)$ in infants of chronic HBsAg mothers are lower than those in our series (5:9 and 4:18); this is not surprising as counter electrophoresis has a lower sensitivity then radioimmunology. ${ }^{1}$

Despite the poor sensitivity of his method, Professor Ozsoylu found HBsAg in 5 of $39(=12.82 \%)$ cases of neonatal hepatitis. This confirms that many cases of neonatal hepatitis in the Mediterranean area are due to hepatitis B virus, and attempts to prevent this dangerous infection in newborn babies at risk are justified.

\section{Reference}

1 Vandervelde E M, Mahmood N, Goffin C, Porter A, Megson B, Cossart Y E. User's guide to some new tests for hepatitis-B antigen. Lancet 1974; ii: 1066-8.

Florindo Mollica, Salvatore Musumeci, AND TEREsa MATTINA

Clinica Pediatrica Università, viale Andrea Doria 6, 95125 Catania, Italy

\section{Carrier detection in Duchenne muscular dystrophy}

Sir,

In a recent article on carrier detection in Duchenne muscular dystrophy, Sibert et al. ${ }^{1}$ concluded that their data support Haldane's rule that one-third of the cases should be due to new mutation. We believe that they have misinterpreted Haldane's statement.

Haldane ${ }^{2}$ showed that of all cases of an X-linked recessive disease in a given generation, a fraction $(1-f) \mu / 2 \mu+v$ should be due to new mutation, where $f=$ fitness of affected boys and $\mu, v$ are mutation rates in eggs and sperm, respectively. For a genetically lethal disease, such as Duchenne muscular dystrophy, $f=0$. If in addition we assume that $\mu=v$ then the familiar form of Haldane's rule results: in each generation, one-third of the cases of a lethal X-linked recessive disease should be due to new mutation.

Instead of using all cases, Sibert et al. ${ }^{1}$ restrict their analysis to mothers of isolated cases. However, the expected proportion of new mutants among isolated cases is not one-third. Since mothers with 2 or more affected sons are obligate carriers, eliminating them results in a group of mothers with an expected proportion of noncarriers greater than one-third. The exact proportion of noncarriers expected depends on the distribution of sibship sizes in the population, but it is always greater than one-third under the same assumptions that lead to Haldane's rule. ${ }^{8}$ Thus, if Sibert et al. ${ }^{1}$ find one-third of the mothers of isolated cases are noncarriers it may be evidence that more cases than expected are inherited. This can result from violation of any of the assumptions under which Haldane's rule is derived. For example, if the mutation rate is higher in sperm than eggs there will be an increased number of women who are carriers because they received a new mutation from their fathers. Evidence that significantly fewer than one-third of Duchenne muscular dystrophy cases are due to new mutation had been presented in several recent reports. ${ }^{4-6}$

\section{References}

1 Sibert J R, Harper P S, Thompson R J, Newcombe R G. Carrier detection in Duchenne muscular dystrophy. Arch Dis Child 1979; 54: 534-7.

2 Haldane J B S. The rate of spontaneous mutation of a human gene. J Genet 1935; 31: 317-26.

3 Chase G A, Murphy E A. Risk of recurrence and carrier frequency for X-linked lethal recessives. Hum Hered 1973; 23: 19-26.

- Pickard N A, Gruemer H-D, Verrill H-L, et al. Systemic membrane defect in the proximal muscular dystrophies. N Engl J Med 1978; 299: 841-6.

5 Roses A D, Roses M J, Miller S E, Hull K L, Appel S H. Carrier detection in Duchenne muscular dystrophy. $N$ Engl J Med 1976; 294: 193-8.

- Bucher K D, Ionasescu V, Hanson J. Frequency of new mutants among boys with Duchenne muscular dystrophy. Am J Med Genet 1980; in press.

K D BUCHER

Department of Preventive Medicine,

V V IONASESCU

Department of Pediatrics, University of Iowa,

Iowa' City,"Iowa"52242, USA 